\title{
The Body of Architecture and its Images
}

\author{
EVA PEREZ DE VEGA
}

The New School \& Pratt Institute
The technical reproduction of images has eviscerated something fundamentally corporeal to the appreciation of artwork and of the architecture that contains it. Prior to its reproducibility, the experiencing of artwork required a full body commitment, even when the artwork itself was twodimensional, it was experienced as three dimensional. One would have to engage with the kinesthetic capacity of our body to appreciate the work. By its very irreproducibility artwork demanded of the viewer a commitment to engage with it using all our senses and with motion.

This paper aims to be a philosophical inquiry into the character of the architectural space that makes viewing artwork images possible. The shift in viewing modes, in the spectator, and in the space, will be explored by zooming into three moments in history with a punctual glance into the changing conception of images, our bodily relationship to them, and the space that contains them.

\section{UNIFIED BODY}

In his treatise on Architecture, Vitruvius puts forth a vision of architecture understood as a unified body ordered through an appreciation of the human body as its regulating system, based on the "optimal proportions" of the human body. His discussions on proportions for architecture in Book Three are dominated by the analogy with the perfectly proportioned male body, known mostly through the translation into an image drawn by Leonardo da Vinci almost a millennium later, the Vitruvian Man. ${ }^{1}$ Interestingly, the new life that was given to his text in the renaissance via illustrations often embodied an agenda quite distinct from that of the roman architect.

Da Vinci's drawing, and the subsequent versions which have been reproduced so exhaustingly, invariably show a standing naked man actively illustrating the proportional relationship between the body and geometrical figures of a circle and a square. It is an undeniably three-dimensional body. But it is worth paying closer attention to Vitruvius' original words:

"For if a man be placed flat on his back, with his hands and feet extended, and a pair of compasses centered at his navel, the fingers and toes of his two hands and feet will touch the circumference of a circle described therefrom. And just as the human body use a circular outline, so to a square figure maybe found from it. For if we measure the distance from the soles of the feet to the top of the head, and then apply that measure to the outstretched arms,

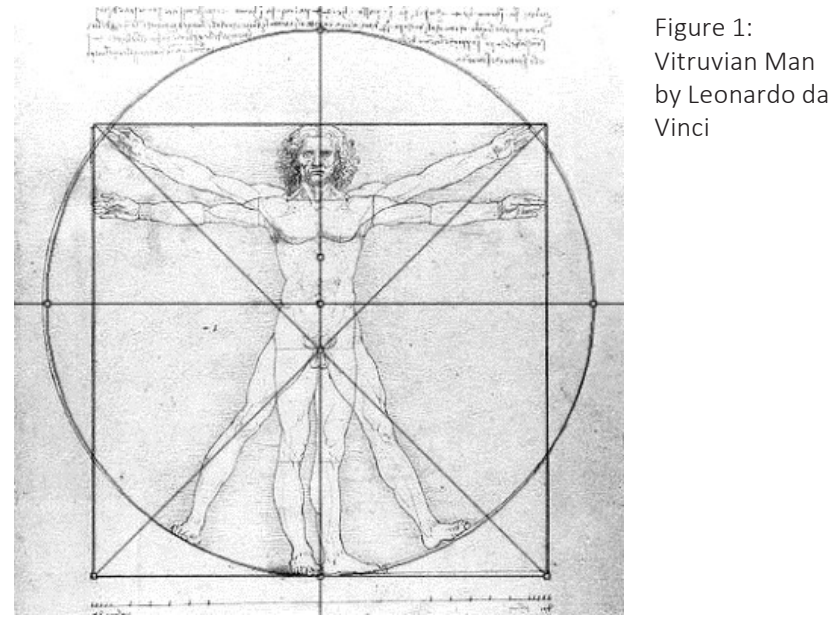

the breath will be found to be the same as the height, as in the case of playing services which are perfectly square."2

While the Vitruvian Man of the Renaissance is invariably illustrated as a standing figure, Vitruvius' description clearly has the man lying down, "placed flat on his back", in a more abstract disposition. He is a man with no thickness, a twodimensional geometric figure used to illustrate proportion and symmetry. The fact that Vitruvius' description had the man lying down indicates a direct correlation between the idealized proportions of the human body and the regulating geometries of the floorplan. His purpose seems to be that of providing a planimetric organizing tool -a diagram-something to be mapped on a floor plan for the correct layout of its proportions. In a sense, the textual man described by Vitruvius is more abstract and two-dimensional than the three-dimensional standing image produced in the Renaissance. We don't know what the drawing would have been like had it been drawn by Vitruvius himself, but we do know it would have had a more direct relationship with a floor plan than with an elevation.

Curiously, what may be obscuring Vitruvius's words is in fact illuminating the humanistic concepts of images during the Renaissance. Illustrating the Vitruvian man as standing instead of lying down is also a consequence of the invention of perspective, a technique of drawing that mimics human cone of vision elevating the human point of view to a privileged position in artwork. With perspective, the subject's particular point of view becomes a central and dominant organizational of space, and thus the change of emphasis from floor plan to perspective seems a natural one, as does a tight 


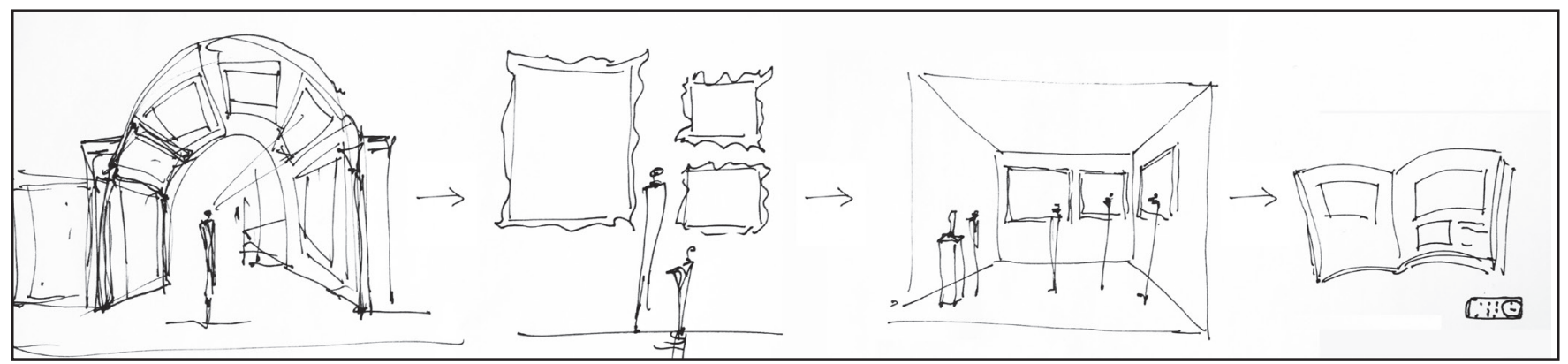

Figure 2: Spaces for art in 4 stages: Full integration [19 Cent.]; Picture Gallery [early 20th Cent.]; white box [20th Cent.]; Individual viewing

correspondence between the human body and architecture. For the Renaissance masters inspired by Vitruvius' writings, the body was the unifying element between abstraction and built space.

\section{DISEMBODIED BODY}

\section{THE EMERGENCE OF THE WHITE BOX SPACE FOR IMAGES}

The architecturally integrated artwork of the sixteenth century, gave way to the "picture gallery" of the eighteenth century where artwork was used to adorn and enhance interior spaces. Thus, while full integration was no longer dominant, there was a reciprocal relationship between the space and the image contained in it insofar as one is used to enhance the other: the picture adorned the spaces, the space enabled the picture to be contemplated with a particular environment, or aura ${ }^{3}$, around it. However, the relationship is no longer held by a tight fit as the two are no longer codependent on one another. There is a slight dissociation between the space and the artwork: the artwork gets framed allowing for its easy transportation and relocation making the space that houses it become associated with temporality rather than permanence. Images and space for contemplation of images are no longer coupled together as in the case of the frescoes of the Renaissance or the mosaics of the middle ages in religious and public places. And as a consequence, the space becomes more two-dimensional.

The loss of dimensionality in the image and in the experience of the image or artwork, that went hand in hand with a flattening of the space that housed them. The rapid reproduction of images at the beginning of the 20th century with photography, allowed for almost complete disassociation between the artwork and the space where it is being shown. In losing the authenticity there is also a loss of what Walter Benjamin calls the "aura"; the connection that all images have when coupled to the space that houses them:

"Even the most perfect reproduction of a work of art is lacking in one element: its presence in time and space, its unique existence at the place where it happens to be." ${ }^{\prime 4}$
With this separation between image and space, there is a distancing between the spectator and the image, giving way to the typology that is most taken for granted, the white cube. Here the walls, ceilings, and floors are deprived of any color beyond a neutral white or grey, resulting in complete dissociation between the artwork and the space. As we arrive to the white cube as an aesthetic device of modernity, it becomes more specifically about vision, and not the complete sensorial experiencing which the architecturally integrated artwork of the sixteenth century demanded. This typology seems to be designed to have a specific ritualistic effect on the viewer; a sense of reverence towards the images on the wall and complete negation of senses other than sight. There is something about its whiteness and "purity" that makes the spectator behave in a particular way; there is a tendency to leave more distance between the viewer and the artwork, and very often talking in a whisper as if it were a place of worship.

\section{THE EMERGENCE OF THE BLACK BOX FOR MOVING IMAGE}

In a parallel with the "white box" for viewing artwork images, the "black box" is still held as the paradigm for optimal viewing of moving images. However, a brief look at the history of this artform will show us that it took between twenty to thirty years of evolution for this particular viewing style, to establish itself as the singular way of consuming moving images. In the 1920s there still was no single viewing style for film. The "cinema" was where the projector was: in a cafe' or a temporary empty garage, under a circus tent, at a fair, on an improvised vaudeville stage. The picture house emerged as a paradoxical space, in which very different and often opposing functions were brought together in a single space, causing the viewer to be in a state of distraction while viewing the movie.

Arriving at the dark identity-less black box space of most contemporary movie-houses took some time, and yet it has persisted. Still today we associate to the movie-going experience with: total darkness, separation from the outside world, immobility and silence, and being in a large communal space with other strangers. There is an implicit and socially-agreed upon understanding that as soon as images are projected on the screen, there are certain behavioral norms to follow and a "right way" to experience a movie and behave during the 


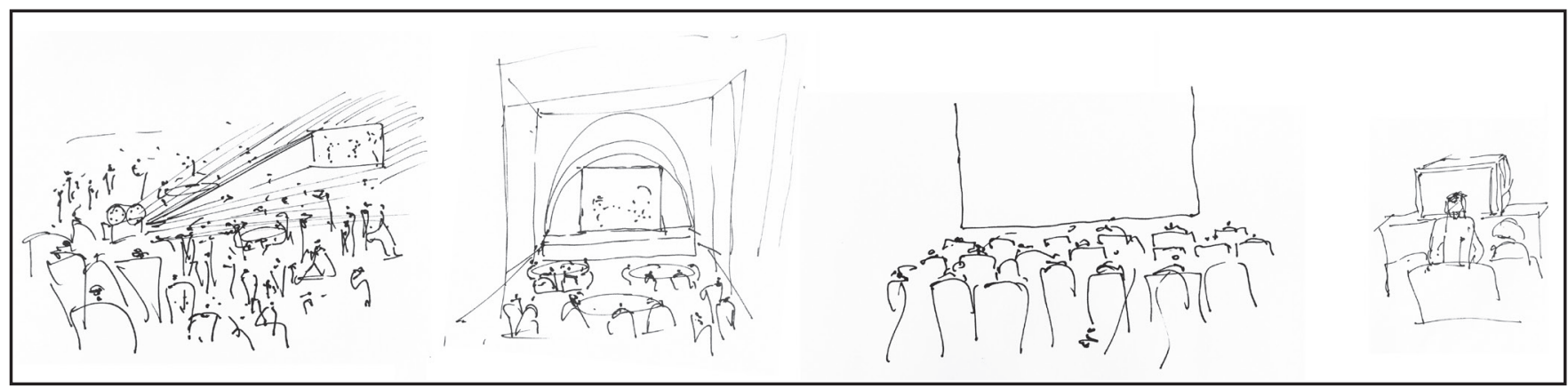

Figure 3: Spaces for movies in 4 stages: Full integration [19 Cent.]; Picture house [early 20th Cent.]; black box [20th Cent.]; Individual viewing

projection of it, which includes cutting off our senses that are not sight or hearing. How did this ritualistic behavior emerge?

Initially, in trying to find the optimal architectural typology for projecting movies there was a push to assimilate the design of the first movie houses in the nineteen twenties, to known theater typologies which derived from Renaissance conceptions of the theater. These conceptions in turn were deeply influenced by the writings of Vitruvius, again based on the optimal proportions of the human body- the unified body conceived through the universal Vitruvian man. The same geometries of a circle and a square rotating inside it around a central point, are used in the diagram of theater design to subdivide and organize the space. ${ }^{5}$ Renaissance conception of architectural organization was departing from the idea of man as likened by gods; religion was being replaced by the human body. It was the humanist unified body discussed earlier, that permeated most aspects of life in this time period, and materialized in the design of spaces for viewing artwork.

In an attempt to bring the viewing styles of cinema and theater closer together and to elicit equal attention, the first designs of the space for cinema in the early twentieth century were inspired by Vitruvian notions that permeated the Italian playhouses, which gave rise to the "vitruvian spectator"6 : someone immersed in the experience of that which is unfolding on the screen, respectful of the physical and communal environment that holds the event, without succumbing to unnecessary distractions. Thus, the physical environment was designed to seem familiar, recall behavioral associations, and instill tight control over the behavior of the spectator. As Pedulla reminds us, there is an awareness of the psychological effects that particular spatial designs can have over the user, and a: "general acknowledgement of the psychological ends of architecture and its ability to control perception."

\section{FRAGMENTED BODY}

\section{ARCHITECTURAL SPACE AND CONTROL: KIESLER AND FREUD}

The assimilation of the Vitruvian theater was fervently questioned by architects, critics, and filmmakers of mid twentieth century who did not agree with using the theater as inspiration for the cinema. Frederick Kiesler pointed to some initial practical reasons for this but emphasized the uniqueness of the "place" for movies:

"the cinema is a play of surfaces, the theatre is a performance in space, and this difference has not yet been translated concretely into any piece of architecture, neither for the theater nor for the cinema." ${ }^{10}$

Unnecessary theatrical elements began to drop away, and the assimilation that was taking place was not about it looking like a theater, but rather affording the same behaviors from the spectator that the theater afforded. Kiesler felt that what was: "The most important quality of an auditorium for film was the ability to suggest concentrated attention" and, importantly, allow the spectator to "lose himself in an infinite imaginary space." This is an important point worth remarking on briefly, and placing into the context of the time which will require a short detour into Freudian thought. ${ }^{11}$

There is a parallel between the movie house and Freudian psychoanalytic techniques: the consulting room of a psychoanalysts is a very tightly controlled space, set up to illicit a certain kind of behavior and response in the patient. The ability to lose oneself into an infinite imaginary space, implies that the feeling of containment that a movie house might initially engender, is replaced by a feeling of oneness when the spectator rests his eyes on the screen, putting him in a condition to "lose himself". This feeling of oneness is similar to Freud's notion of oceanic feeling ${ }^{12}$ which refers to a state of oneness with the universe; one of the aims of psychoanalytic sessions.

A successful analytic session embarks in free association and analytic interpretation in order to instigate transference and regression. While all that visibly takes place in a session is the verbal exchange of words ${ }^{13}$ environmental factors also play a key role in triggering the regressive state. The space of analysis 


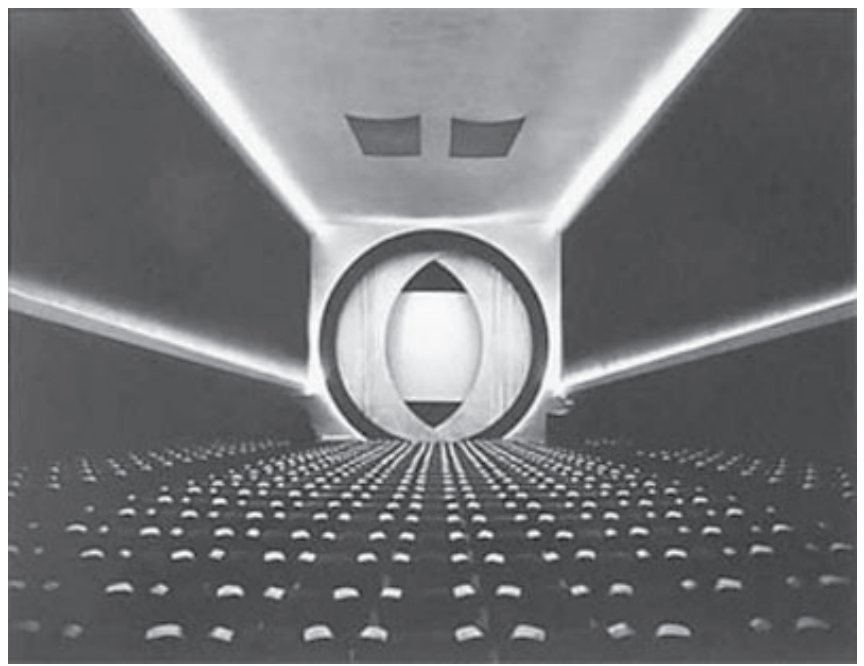

Figure 4: Frederick Kiesler, Film Guild Cinema in New York City

is not just a passive context for treatment; it is an active participant in the analysis. The room activates daydreaming while protecting and sheltering the daydreamer, functioning as a safe haven and shelter for the patient but also as a stimulant of regression. The aim of the spatial setup of the consultation room is to imbue the patient with a feeling of 'the uncanny', a concept developed by Freud in his 1919 paper of the same name. The use of the couch, the controlled visual, auditory and tactile environment- is to simultaneously disorient and orient, confuse and enlighten, frighten and shelter the patient. It evokes simultaneous opposing -yet not contradictory- sensations which extract the patient from his or her particular perspective of reality and re-orients the patient into a state of fusion with the space itself. This, together with the words of the analyst, is instrumental in propelling the patient to lose himself in the space, allowing the space itself to recede and the words to come to the fore. This oscillating movement between opposing states causes a reorientation of the patient towards the primal oceanic feeling of oneness - towards a state of fusion with the space itself, inducing regression into the unconscious. It seems that Kiesler is making reference to the ability that physical environment has to create a palpable effect and feeling of oneness on the spectator.

\section{ARCHITECTURE AS AN AESTHETIC DEVICE}

After decades of aiming to find its place movies seemed to have an established location in the black box space. The auditorium's principal objective for the vitruvian spectator was to impose on the audience a new attitude towards movies, by subjecting spectators to total darkness and voluntarily restricting freedom of movement. Yet, as any contemporary moviegoer knows, cinema is undergoing the same crises that artwork images did once they reached the age of massive reproduction. Given the prevalence of technology that allows the streaming of movies in our own homes, film is now reproducible at the level of the individual, who is able to project a film without the apparatus of the cinema. Thus, the ceremonial quality of the cinema and its uniqueness is now lost. ${ }^{14}$ It is no longer enough to just project a movie to entice people to go to the movies. Cinema is poised to find itself a new kind of space.

The appreciation of artwork today is multifaceted and fragmented. Our screens and access to information allow us to have multiple scales of appreciation: we can look at the image of an art piece by zooming into its pixels on a computer or tablet, and also remotely experience the way in which the piece is being displayed by literally panning the globe on our screens to understand its context and physical location in the world. This is a fragmentation emerges, not as an opposition to unity, but as repetition of different scales of appreciation, which overlap and juxtapose different information to create a unity of the fragmented. Our appreciation of images is fragmented through repetition and difference yet we can achieve a full understanding of the work of art through these multiple scales available to us.

However, there is still a persistent sensorial distance that these remote modes of appreciation instill. No matter how close we can zoom into an image on our screens, we will not be able to feel the texture of the space where it is hanging, or hear the quiet whispers of fellow visitors to the gallery, or be affected by the myriad environmental and physical factors that distracted the spectator of a fresco, as described earlier in the cases where artwork is fully integrated with the architectural space that houses it. Through our devices it is possible that we might gain access to aspects of the work that may not be available when visiting in person, but that intangible and yet highly present "aura" which one feels when in direct contact with an artwork image cannot really be substituted by any device.

There have certainly been attempts to re-introduce this bodily three-dimensional sensorial quality back into the experience of viewing images on screens, in order to make it "more real". The aim to re-introduce of the third dimension that was seemingly lost in photography and cinema, has sparked the proliferation of $3 \mathrm{~d}$ movies or cinema in four dimensions, attempting to envelope the spectator in a full-body sensorial experience. Enabled by technology, movie houses are aiming to reinvent the experience with immersive cinema, to make the experience more "real", more three-dimensional.

Paradoxically, with this attempt to provide a more realistic experience, we are constantly reminded of its artificiality. In $3 \mathrm{~d}$ movies we are obliged to wear awkward glasses to perceive the three-dimensional information. If we were to remove them nothing but a blurred vision of what is being projected would be perceivable. Thus, in aiming to make the experience more bodily by adding the third dimension of space, we are only able to perceive it through a device that is external to our body, the $3 \mathrm{~d}$ glasses. On the other hand, when we are provided with the added sensorial perks of a shivering seat, 
or a puff of air suddenly blowing in our face, rather than being immersed by the experience we are reminded of the absurdity of the artifice gone into creating the still awkward effect.

While this $4 d$ technology is still very much in development, with the advent of the digital in image making we are undoubtedly in a different place than when images became reproducible via photography or film. It appears that the control is now in the hands of the spectator, able to choose between very different modes of viewership. How can we think about images in the same way now that we are in the post digital-reproducibility era?

Virtual reality has been one of the new ways to experience images, whether of art, movies or of an entirely different nature, mostly related to gaming. But virtual reality relies on the wearing of devices, usually around the eyes, that shut the physical world out in order to experience an intangible world almost purely through a visual register. The privileging of the visual is exacerbated to such a degree in virtual reality that it denies the multi-sensorial body that enables us to navigate the world. Which might be why it is successful in gaming but not so much in the experience of art.

"Augmented reality" does something different. Rather than making us inhabit a reality that is virtual, denying the body, it brings the virtual into our physical world, supposedly augmenting the real. In augmented reality, we are not denying the physicality of our bodies. Instead of trying to mimic the physical environment virtually by shutting off the world, there is a re-framing of the physical with the introduction of the virtual: we see the physical anew. To some important degree, it signals a return to the appreciation of the physical environment in which our images found themselves prior to their irreproducibility. The images need the physical qualities of the space in order to be understood, there is an inter-dependence between the space and the virtual image that inhabits that space.

\section{CONCLUDING REMARKS}

By zooming into three moments in history (the Renaissance, the beginning of the 20th century and our current condition starting at the end of the 20th century) we have traced a successive distancing from the physical body: going from a united conception of images, body and space, to a disembodied one separating body and space, to a fragmented one enabled by the pervasiveness of the digital. We have also seen that built spaces to house artwork, both still images and moving images, have served as aesthetic devices to either tightly, or more loosely, control and affect the spectator.

Paradoxically today, while we seem to be in a moment where almost everything can be experienced virtually, the evolution of digital technology is almost nostalgically pointing us back to the times when we depended on our bodies moving through space in order to appreciate the image. With the overabundance of reproduction techniques, enabled by the digital, we are paradoxically returning to the conception of images we had before images could be reproduced with the rapidity that contemporary methods allow. As we have seen: in virtual reality, the device is what controls our experience by shutting off most of our senses and privileging the visual; while in augmented reality, we are not denying the physicality and the multi-sensorial quality of our world. Architectural space is still, curiously, the aesthetic device that it was during the Renaissance.

While there is no singular overarching conception of how images are to be experienced today, there certainly is an attempt to regain the loss of dimension implicit in image reproduction, by reintroducing the experiential and sensorial dimension back into the appreciation of art. It seems however, that the cinema and the art gallery are still in search for a new typology fit for the fragmented spectator.

\section{ENDNOTES}

1 In the context of this paper, drawings and diagrams are considered images.

2 Vitruvius The Ten Books of Architecture, Book 3: On symmetry, 73.

3 This is an explicit reference to the work of Walter Benjamin "The Work of Art in the Age of Mechanical Reproduction". While Benjamin's text is of huge value to the development of the ideas in this text, there is also an understanding of the work of art which this text moves away from in favor of a multifaceted understanding of how art can be appreciated. To quote Gabiele Pedulla: "Contrary to what Benjamin thought, there is more than one way to appreciate the work of an architect, to go to the theater, or to look at a painting. If this were not the case, there would be no need for aesthetic devices like the dark cube in the first place." In Broad Daylight, 73.

4 Walter Benjamin "The Work of Art in the Age of Mechanical Reproduction" (1936).

5 Theater design is covered in Book 5 of Vitruvius' text. As Pedulla states: For Renaissance humanists, educating the public in the classical theater was part of a much more comprehensive project of recreating man in the likeness of the Greek and Romans. Gabriele Pedulla, In Broad Daylight, 47.

6 This is the title of a chapter in Gabriele Pedulla's book In Broad Daylight, 37-60.

7 As Leon Battista Alberti claimed: "The architects only task was to put the spectators in a condition to see and hear effortlessly what was happening on stage." Leon Battista Alberti, The Art of Building in Ten Books. In Latin, De reAedificatoria c. 1443.

8 Certainly, the shift in the type of space was also enabled by the kinds of movies that required more attention, and were based on narration. However, they could not have emerged without a concerted effort to control the viewer's perception of space through the careful design and associative power that physical space has on the subject, and the subject's capacity to appreciate the object. To quote Pedulla further: "Imitating the theater, the dark cube in fact aspired to propose itself as a place of absolute aesthetic experience that allowed only one legitimate activity: the contemplation of a film. (...) Suddenly, going to the movies was like going to church." Gabriele Pedulla, In Broad Daylight, 33.

9 For instance; in a movie house, the first rows were no longer the best ones, as in the theater; the side seating provided by elegant boxes also become nonsensical for the viewing of a flat screen which is best viewed frontally; and similarly, the typical fan-shaped seating of the theater house did not provide the best view for the flat screen.

10 Friederick Kiesler quoted by Gabriele Pedulla, In Broad Daylight, 51-52.

11 It is interesting to note that Kiesler and Freud were both from Vienna and Kiesler being thirty-four years younger implies that his working years were in a fully Freud-imbued Vienna.

12 Freud first refers to the 'oceanic feeling' in Civilization and its Discontents, in the context of letters exchanged with his friend, now known to be Romain Rolland: "It is a feeling which he would like to call a sensation of 'eternity', a feeling as of something limitless, unbounded-as it were, 'oceanic,'” 11.

13 As Lacan put it "reducing it to its bare truth (...) it is merely a question of words spoken". Jacques Lacan, "The Direction of the Treatment and The Principles Of Its Power" in Ecrit: A Selection, 227. 